\title{
A Stochastic Predator-Prey System with Stage Structure for Predator
}

\author{
Shufen Zhao ${ }^{1,2}$ and Minghui Song ${ }^{1}$ \\ ${ }^{1}$ Department of Mathematics, Harbin Institute of Technology, Harbin 150001, China
}

${ }^{2}$ Department of Mathematics, Zhaotong University, Zhaotong 657000, China

Correspondence should be addressed to Shufen Zhao; zhaoshufen@gmail.com

Received 20 February 2014; Accepted 8 April 2014; Published 30 April 2014

Academic Editor: Weiming Wang

Copyright (c) 2014 S. Zhao and M. Song. This is an open access article distributed under the Creative Commons Attribution License, which permits unrestricted use, distribution, and reproduction in any medium, provided the original work is properly cited.

The authors introduce stochasticity into a predator-prey system with Beddington-DeAngelis functional response and stage structure for predator. We present the global existence and positivity of the solution and give sufficient conditions for the global stability in probability of the system. Numerical simulations are introduced to support the main theoretical results.

\section{Introduction}

The classical predator-prey model with BeddingtonDeAngelis type functional response can be denoted as

$$
\begin{aligned}
& \dot{x}(t)=x\left[b_{1}-a_{11} x-\frac{a_{12} y}{1+m x+n y}\right], \\
& \dot{y}=y\left[-b_{2}+\frac{a_{21} x}{1+m x+n y}-a_{22} y\right],
\end{aligned}
$$

where $x(t)$ and $y(t)$ represent predator and prey densities at time $t$, respectively. $b_{i}, a_{i j}, m$, and $n$ are positive constants, $i$, $j=1,2$. For biological representation of each coefficient in (1) we refer the reader to $[1,2]$. In model (1), it is assumed that all individuals of a single species have largely similar capabilities to hunt or to reproduce. But the life cycle of most animals consists of at least two stages, immature and mature, and the individuals in the first stage often can neither hunt or reproduce, being raised by their mature parents and there are recognizable morphological and behavioral differences that may exist between these stages. In [3], the authors studied the global properties of a predator-prey model with nonlinear functional response and stage structure for the predator, and the condition of the existence and the global stability of the positive steady states were established. However, May [4] pointed out that due to environment noise, the birth rate, carrying capacity, competition coefficients, and other parameters involved in the system exhibit random fluctuation to a greater or lesser extent. So, a lot of authors introduced stochastic noise into deterministic models to reveal the effect of environmental variability on the population dynamics in mathematical ecology [5-7]. In Liu and Wang [5], the authors investigated the global stability of stage-structured predatorprey models with Beddington-DeAngelis type functional response and with stage structure for the prey. The authors [5] also pointed out that there are some technical obstacles that cannot be overcome at present to investigate the stage structure on predator model. So, in this paper we are going to do some work on this problem. The following model,

$$
\begin{gathered}
\frac{\mathrm{d} x}{\mathrm{~d} t}=x\left(\gamma-\frac{q y_{2}}{1+m x+n y_{2}}-\beta x\right), \\
\frac{\mathrm{d} y_{1}}{\mathrm{~d} t}=\alpha y_{2}-d_{1} y_{1}-a_{1} y_{1}^{2}-b y_{1}, \\
\frac{\mathrm{d} y_{2}}{\mathrm{~d} t}=b y_{1}-d_{2} y_{2}-a_{2} y_{2}^{2}+\frac{p y_{2} x}{1+m x+n y_{2}},
\end{gathered}
$$

is derived under the following assumptions.

(H1) The immature predator population $y_{1}$ : the birth rate into the immature population is proportional to 
the existing mature predator population with probability $\alpha>0$; the death rate is proportional to the existing immature predator population with proportionality $d_{1}>0$; overcrowding rate of the immature predator population is $a_{1}>0$; the transformation rate from the immature predator to mature predator is proportional to the existing immature predator population with proportionality $b>0$.

(H2) The mature predator population $y_{2}: d_{2}>0$ and $a_{2}>0$ are the death rate and the overcrowding rate of the mature predator population, respectively, and only the mature predator population feeds the prey. It seems reasonable that a number of mammals, who are immature predators, are raised by their parents. $p / q$ is the rate of conversion of nutrients into the reproduction of the predator.

(H3) The prey population $x$ : the growth of the species is of the Lotka-Volterra nature and $\gamma>0$ is the birth rate; $\beta>0$ is the overcrowding rate. $q>0$ is the capturing rate of the predator.

System (2) is greatly different from the model investigated in [3] for we comprehend that the effect of the response function will diminish the death rate of the predator and the predator does not only feed on the prey.

Suppose that $\left(x^{*}, y_{1}^{*}, y_{2}^{*}\right)$ is a positive equilibrium of (2). If we take the environmental noise into account, we can replace the birth rate of prey population and death rate of predator population by an average value plus a random fluctuation, respectively,

$$
\begin{gathered}
\gamma+\sigma\left(x-x^{*}\right) \dot{B}(t), \\
d_{1}+\sigma_{1}\left(y_{1}-y_{1}^{*}\right) \dot{B}_{1}(t), \\
d_{2}+\sigma_{2}\left(y_{2}-y_{2}^{*}\right) \dot{B}_{2}(t),
\end{gathered}
$$

where $\sigma^{2}, \sigma_{1}^{2}, \sigma_{2}^{2}$ represent the intensities of the noise and $\dot{B}(t)$, $\dot{B}_{1}(t), \dot{B}_{2}(t)$ are standard white noise; namely, $B(t), B_{1}(t), B_{2}(t)$ are standard Brownian motion defined on a complete probability space $(\Omega, \mathscr{F}, P)$ with a filtration $\left\{\mathscr{F}_{t}\right\}_{t \in \mathbf{R}}$ satisfying the usual condition (i.e., it is right continuous and increasing while $\mathscr{F}_{0}$ contains all $P$-null sets). So the corresponding stochastic system of (2) is

$$
\begin{aligned}
\mathrm{d} x= & x\left(\gamma-\frac{q y_{2}}{1+m x+n y_{2}}-\beta x\right) \mathrm{d} t \\
& +\sigma x\left(x-x^{*}\right) \mathrm{d} B(t), \\
\mathrm{d} y_{1}= & \left(\alpha y_{2}-d_{1} y_{1}-a_{1} y_{1}^{2}-b y_{1}\right) \mathrm{d} t \\
& +\sigma_{1} y_{1}\left(y_{1}-y_{1}^{*}\right) \mathrm{d} B_{1}(t), \\
\mathrm{d} y_{2}= & \left(b y_{1}-d_{2} y_{2}-a_{2} y_{2}^{2}+\frac{p x y_{2}}{1+m x+n y_{2}}\right) \mathrm{d} t \\
& -\sigma_{2} y_{2}\left(y_{2}-y_{2}^{*}\right) \mathrm{d} B_{2}(t),
\end{aligned}
$$

with the initial condition $\left(x(0), y_{1}(0), y_{2}(0)\right) \in \mathbf{R}_{+}^{3}$ where $\mathbf{R}_{+}^{3}=\left\{x \in \mathbf{R}^{3} \mid x, y_{1}, y_{2}>0, i=1,2,3\right\}$.
The paper is organized as follows. In Section 2, we prove the existence, uniqueness, and the positivity of the solution to (4). In Section 3, we established the condition for the global stability of the positive equilibrium. We work out two simulation figures to illustrate our main results in Section 4. Section 5 gives the conclusions and future directions.

\section{Existence of the Global Positive Solution}

Theorem 1. For any initial value $\left(x(0), y_{1}(0), y_{2}(0)\right) \in \mathbf{R}_{+}^{3}$, system (4) has a unique global positive solution $\left(x(t), y_{1}(t), y_{2}(t)\right)$ on $t>0$ with probability one.

Proof. We see that the coefficients of the system are locally Lipschitz continuous, so, for any given initial values $x(0)>0$, $y_{1}(0)>0, y_{2}(0)>0$, there is a unique maximal local solution $\left(x(t), y_{1}(t), y_{2}(t)\right)$ on $t \in\left[0, \tau_{e}\right)$, where $\tau_{e}$ is the explosion time [8]. To show this solution is global, we need to show that $\tau_{e}=$ $\infty$. Define the stopping time by

$$
\begin{gathered}
\tau_{k}=\inf \left\{t \in(0, \infty), y_{i}(t)=\frac{1}{k}\right. \\
\text { or } y_{i}(t)=k, \quad i=1,2, \\
\text { or } \left.x(t)=\frac{1}{k} \text { or } x(t)=k\right\},
\end{gathered}
$$

where, throughout this paper, we set inf $\emptyset=\infty$. Clearly, $\tau_{k}$ is increasing as $k \rightarrow \infty$. Set $\tau_{\infty}=\lim _{k \rightarrow \infty} \tau_{k}$, whence $\tau_{\infty} \leq \tau_{e}$ a.s. If we can show that $\tau_{\infty}=\infty$ a.s., then $\tau_{e}=\infty$ a.s. Namely, to complete the proof, it is sufficient to show that $\tau_{\infty}=\infty$ a.s. If this statement is false, then there is a pair of constants $T>0$ and $\epsilon \in(0,1)$, such that $P\left\{\tau_{\infty} \leq T\right\}>\epsilon$. Hence, there is an integer $k_{1} \geq k_{0}$ such that

$$
P\left\{\tau_{k} \leq T\right\} \geq \epsilon \quad \forall k \geq k_{1},
$$

where $k_{0}$ is satisfying $1 / k_{0}<y_{i}(0)<k_{0}, i=1,2$, and $1 / k_{0}<$ $x(0)<k_{0}$.

Define a $C^{2}$-function $V: \mathbf{R}_{+}^{3} \rightarrow \mathbf{R}_{+}$by

$$
\begin{aligned}
V\left(x, y_{1}, y_{2}\right)= & (\sqrt{x}-1-0.5 \ln x)+\left(\sqrt{y_{1}}-1-0.5 \ln y_{1}\right) \\
& +\left(\sqrt{y_{2}}-1-0.5 \ln y_{2}\right) .
\end{aligned}
$$

Using Itô's formula, we get

$$
\begin{aligned}
\mathrm{d} V= & \frac{1}{2}\left(x^{-1 / 2}-x^{-1}\right) \cdot \mathrm{d} x+\frac{1}{2}\left(y_{1}^{-1 / 2}-y_{1}^{-1}\right) \cdot \mathrm{d} y_{1} \\
& +\frac{1}{2}\left(y_{2}^{-1 / 2}-y_{2}^{-1}\right) \cdot \mathrm{d} y_{2} \\
& +\frac{1}{2}\left(-\frac{1}{4} x^{-3 / 2}+\frac{1}{2} x^{-2}\right) \cdot(\mathrm{d} x)^{2} \\
& +\frac{1}{2}\left(-\frac{1}{4} y_{1}^{-3 / 2}+\frac{1}{2} y_{1}^{-2}\right) \cdot\left(\mathrm{d} y_{1}\right)^{2} \\
& +\frac{1}{2}\left(-\frac{1}{4} y_{2}^{-3 / 2}+\frac{1}{2} y_{2}^{-2}\right) \cdot\left(\mathrm{d} y_{2}\right)^{2}
\end{aligned}
$$




$$
\begin{aligned}
L V= & \frac{1}{2}\left(x^{1 / 2}-1\right)\left(\gamma-\frac{q y_{2}}{1+m x+n y_{2}}-\beta x\right) \\
& +\frac{1}{2}\left(-\frac{1}{4} x^{1 / 2}+\frac{1}{2}\right) \sigma^{2}\left(x-x^{*}\right)^{2} \\
& +\frac{1}{2}\left(y_{1}^{-1 / 2}-y_{1}^{-1}\right)\left(\alpha y_{2}-d_{1} y_{1}-a_{1} y_{1}^{2}-b y_{1}\right) \\
& +\frac{1}{2}\left(-\frac{1}{4} y_{1}^{1 / 2}+\frac{1}{2}\right) \sigma_{1}^{2}\left(y_{1}-y_{1}^{*}\right)^{2} \\
& +\frac{1}{2}\left(y_{2}^{-1 / 2}-y_{2}^{-1}\right) \\
& \times\left(b y_{1}-d_{2} y_{2}-a_{2} y_{2}^{2}+\frac{p x y_{2}}{1+m x+n y_{2}}\right) \\
& +\frac{1}{2}\left(-\frac{1}{4} y_{2}^{1 / 2}+\frac{1}{2}\right) \sigma_{2}^{2}\left(y_{2}-y_{2}^{*}\right)^{2} \\
= & \frac{1}{2}\left(x^{1 / 2}-1\right)\left(\gamma-\frac{q y_{2}}{1+m x+n y_{2}}-\beta x\right) \\
& +\frac{1}{2}\left(y_{2}^{-1 / 2}-y_{2}^{-1}\right) b y_{1}+\frac{1}{2}\left(y_{1}^{-1 / 2}-y_{1}^{-1}\right) \alpha y_{2} \\
& +\frac{1}{2}\left(y_{1}^{1 / 2}-1\right)\left(-d_{1}-a_{1} y_{1}-b\right) \\
& +\frac{1}{2}\left(-\frac{1}{4} y_{2}^{1 / 2}+\frac{1}{2}\right) \sigma_{2}^{2}\left(y_{2}-y_{2}^{*}\right)^{2} . \\
& +\frac{1}{2}\left(y_{2}^{1 / 2}-1\right)\left(-d_{2}-a_{2} y_{2}+\frac{1}{1+m x+n y_{2}}\right) \\
& +\frac{1}{2}\left(-\frac{1}{4} x^{1 / 2}+\frac{1}{2}\right) \sigma^{2}\left(x-x^{*}\right)^{2} \\
& \left.+\frac{1}{2}\right) \sigma_{1}^{2}\left(y_{1}-y_{1}^{*}\right)^{2} \\
& \left.\frac{1}{2}\right)
\end{aligned}
$$

Now, we pay attention to the term $(1 / 2)\left(y_{1}^{-1 / 2}-y_{1}^{-1}\right) \alpha y_{2}$. If $y_{1}<1$, then $(1 / 2)\left(y_{1}^{-1 / 2}-y_{1}^{-1}\right) \alpha y_{2}<0$, so, this term can be omitted from the right side of the inequality. If $y_{1}>1$, then $(1 / 2)\left(y_{1}^{-1 / 2}-y_{1}^{-1}\right) \alpha y_{2}<(1 / 2)\left(y_{1}^{1 / 2}-1\right) \alpha y_{2}$. The similar argument can be taken on $(1 / 2)\left(y_{2}^{-1 / 2}-y_{2}^{-1}\right) b y_{1}$. So we get the following inequality:

$$
\begin{aligned}
L V \leq & \frac{1}{2}\left[-\beta x^{3 / 2}+\beta x+\gamma x^{1 / 2}+\frac{q}{n}-\gamma\right] \\
& +\frac{b}{2} y_{1}\left(\sqrt{y_{2}}-1\right)+\frac{\alpha}{2} y_{2}\left(\sqrt{y_{1}}-1\right) \\
& +\frac{1}{2}\left[-a_{1} y_{1}^{3 / 2}-\left(d_{1}+b\right) y_{1}^{1 / 2}+a_{1} y_{1}+d_{1}+b\right] \\
& +\frac{1}{2}\left[-a_{2} y_{2}^{3 / 2}+\left(\frac{p}{n}-d\right) y_{2}^{1 / 2}+a_{2} y_{2}+d_{2}\right]
\end{aligned}
$$

$$
\begin{aligned}
& +\frac{1}{2} \sigma^{2}\left(-\frac{1}{4} x^{5 / 2}+\frac{1}{2} x^{2}+\frac{1}{2} x^{*} x^{3 / 2}\right. \\
& \left.-x^{*} x-\frac{1}{4} x_{2}^{* 2} x^{1 / 2}+\frac{1}{2} x_{2}^{* 2}\right) \\
& +\frac{1}{2} \sigma_{1}^{2}\left(-\frac{1}{4} y_{1}^{5 / 2}+\frac{1}{2} y_{1}^{2}+\frac{1}{2} y_{1}^{*} y_{1}^{3 / 2}\right. \\
& \left.-y_{1}^{*} y_{1}-\frac{1}{4} y_{1}^{* 2} y_{1}^{1 / 2}+\frac{1}{2} y_{1}^{* 2}\right) \\
& +\frac{1}{2} \sigma_{2}^{2}\left(-\frac{1}{4} y_{2}^{5 / 2}+\frac{1}{2} y_{2}^{2}+\frac{1}{2} y_{2}^{*} y_{2}^{3 / 2}\right. \\
& \left.-y_{2}^{*} y_{2}-\frac{1}{4} y_{2}^{* 2} y_{2}^{1 / 2}+\frac{1}{2} y_{2}^{* 2}\right) \\
& \leq \frac{1}{2}\left[-\beta x^{3 / 2}+\beta x+\gamma x^{1 / 2}+\frac{q}{n}\right] \\
& +\frac{1}{2}\left[\frac{b}{2} y_{1}^{2}-a_{1} y_{1}^{3 / 2}-\left(d_{1}+b\right) y_{1}^{1 / 2}\right. \\
& \left.+\left(a_{1}-b+\frac{\alpha}{2}\right) y_{1}+d_{1}+b\right] \\
& +\frac{1}{2}\left[\frac{\alpha}{2} y_{2}^{2}-a_{2} y_{2}^{3 / 2}+\left(\frac{p}{n}-d\right) y_{2}^{1 / 2}\right. \\
& \left.+\left(a_{2}-\alpha+\frac{b}{2}\right) y_{2}+d_{2}\right] \\
& +\frac{1}{2} \sigma^{2}\left(-\frac{1}{4} x^{5 / 2}+\frac{1}{2} x^{2}+\frac{1}{2} x^{*} x^{3 / 2}\right. \\
& \left.-x^{*} x-\frac{1}{4} x_{2}^{* 2} x^{1 / 2}+\frac{1}{2} x_{2}^{* 2}\right) \\
& +\frac{1}{2} \sigma_{1}^{2}\left(-\frac{1}{4} y_{1}^{5 / 2}+\frac{1}{2} y_{1}^{2}+\frac{1}{2} y_{1}^{*} y_{1}^{3 / 2}\right. \\
& \left.-y_{1}^{*} y_{1}-\frac{1}{4} y_{1}^{* 2} y_{1}^{1 / 2}+\frac{1}{2} y_{1}^{* 2}\right) \\
& +\frac{1}{2} \sigma_{2}^{2}\left(-\frac{1}{4} y_{2}^{5 / 2}+\frac{1}{2} y_{2}^{2}+\frac{1}{2} y_{2}^{*} y_{2}^{3 / 2}\right. \\
& \left.-y_{2}^{*} y_{2}-\frac{1}{4} y_{2}^{* 2} y_{2}^{1 / 2}+\frac{1}{2} y_{2}^{* 2}\right)
\end{aligned}
$$

$\leq K$,

where $K$ is positive constant. Integrating both sides of (8) from 0 to $\tau_{k} \wedge T$ and then taking the expectations lead to

$$
\begin{gathered}
V\left(x\left(\tau_{k} \wedge T\right), y_{1}\left(\tau_{k} \wedge T\right), y_{2}\left(\tau_{k} \wedge T\right)\right) \\
\leq V\left(x(0), x_{1}(0), y_{2}(0)\right)+K T .
\end{gathered}
$$

Setting $\Omega_{k}=P\left\{\tau_{k} \leq T\right\}$ for $k \geq k_{1}$, then by the inequality (6) we have $P\left(\Omega_{k}\right) \geq \epsilon$; note that for every $\omega \in \Omega_{k}$, $V\left(x\left(\tau_{k}, \omega\right), y_{1}\left(\tau_{k}, \omega\right), y_{2}\left(\tau_{k}, \omega\right)\right)$ is no less than $\min \{\sqrt{k}-1-$ $0.5 \ln k, \sqrt{1 / k}-1-0.5 \ln (1 / k)\}$. 
It then follows from (11) that

$$
\begin{aligned}
& E\left[I_{\Omega_{k}} V\left(x\left(\tau_{k}\right), x_{1}\left(\tau_{k}\right), y_{2}\left(\tau_{k}\right)\right)\right] \\
& \quad \leq V\left(x(0), y_{1}(0), y_{2}(0)\right)+K T,
\end{aligned}
$$

where $I_{\Omega_{k}}$ is the indicator function of $\Omega_{k}$ and $E\left[I_{\Omega_{k}} V\left(x\left(\tau_{k}\right), y_{1}\left(\tau_{k}\right), y_{2}\left(\tau_{k}\right)\right)\right] \geq \epsilon \min \{\sqrt{k}-1-0.5 \ln k$, $\sqrt{1 / k}-1-0.5 \ln (1 / k)\}$. So,

$$
\begin{gathered}
\epsilon \min \left\{\sqrt{k}-1-0.5 \ln k, \sqrt{\frac{1}{k}}-1-0.5 \ln \frac{1}{k}\right\} \\
\leq V\left(x, y_{1}(0)(0), y_{2}(0)\right)+K T .
\end{gathered}
$$

Letting $k \rightarrow \infty$ leads to the contradiction

$$
\infty>V\left(x(0), y_{1}(0), y_{2}(0)\right)+K T \geq \infty .
$$

This contradiction shows that $\tau_{\infty}=\infty$, which completes the proof.

\section{Global Behavior}

Suppose $z=z(t)$ is the solution of the following $n$ dimensional stochastic differential equation:

$$
\mathrm{d} z(t)=f(z(t), t) \mathrm{d} t+g(z(t), t) \mathrm{d} B(t),
$$

and $z^{*}$ is the equilibrium position of (15).

From the stability theory of stochastic differential equations, we only need to find a Lyapunov function $V(z)$ satisfying $L V(z) \leq 0$ and the identity holds if and only if $z=z^{*}$ [9], where $z=z(t)$ is the solution of the $n$-dimensional stochastic differential equation (15) and $d V(x(t), t)=L V d t+$ $V_{x}(x(t), t) g(t) d B(t)$.

Theorem 2. If $a_{1}-\left(\sigma_{1}^{2} / 2\right)>0, a_{2}-\left(\sigma_{2}^{2} / 2\right)>0$, and $\beta-\left(\sigma^{2} / 2\right)-$ $\left(q m y_{2}^{*} /\left(1+m x^{*}+n y_{2}^{*}\right)\right)>0$, then the positive equilibrium $\left(x^{*}, y_{1}^{*}, y_{2}^{*}\right)$ of model (4) is globally asymptotically stable with probability one.

Proof. System (4) can be rewritten as

$$
\begin{aligned}
\mathrm{d} x= & \frac{q x\left[m y_{2}^{*}\left(x-x^{*}\right)-\left(1+m x^{*}\right)\left(y_{2}-y_{2}^{*}\right)\right]}{\left(1+m x+n y_{2}\right)\left(1+m x^{*}+n y_{2}^{*}\right)} \mathrm{d} t \\
& -\beta x\left(x-x^{*}\right) \mathrm{d} t+\sigma x\left(x-x^{*}\right) \mathrm{d} B(t), \\
\mathrm{d} y_{1}= & \frac{\alpha}{y_{1}^{*}}\left[y_{1}\left(y_{2}-y_{2}^{*}\right)-y_{2}\left(y_{1}-y_{1}^{*}\right)\right] \mathrm{d} t \\
& -a_{1} y_{1}\left(y_{1}-y_{1}^{*}\right) \mathrm{d} t+\sigma_{1} y_{1}\left(y_{1}-y_{1}^{*}\right) \mathrm{d} B_{1}(t), \\
\mathrm{d} y_{2}= & \frac{b}{y_{2}^{*}}\left[y_{2}\left(y_{1}-y_{1}^{*}\right)-y_{1}\left(y_{2}-y_{2}^{*}\right)\right] \mathrm{d} t \\
& +\frac{p y_{2}\left[\left(1+n y_{2}^{*}\right)\left(x-x^{*}\right)-n x^{*}\left(y_{2}-y_{2}^{*}\right)\right]}{\left(1+m x+n y_{2}\right)\left(1+m x^{*}+n y_{2}^{*}\right)} \mathrm{d} t \\
& -a_{2} y_{2}\left(y_{2}-y_{2}^{*}\right) \mathrm{d} t+\sigma_{2} y_{2}\left(y_{2}-y_{2}^{*}\right) \mathrm{d} B_{2}(t) .
\end{aligned}
$$

Define

$$
\begin{aligned}
V\left(x_{1}, x_{2}, y\right)= & c_{1}\left(x-x^{*}-x^{*} \ln \left(\frac{x}{x^{*}}\right)\right) \\
& +c_{2}\left(y_{1}-y_{1}^{*}-y_{1}^{*} \ln \left(\frac{y_{1}}{y_{1}^{*}}\right)\right) \\
& +c_{3}\left(y_{2}-1-y_{2}^{*} \ln \frac{y_{2}}{y_{2}^{*}}\right),
\end{aligned}
$$

where $c_{i}(i=1,2,3)$ are positive numbers to be determined. Applying Itô's formula to system (16) gives

$$
\begin{aligned}
& L V=c_{2}\left\{\left(y_{1}-y_{1}^{*}\right) \frac{\alpha}{y_{1}^{*}}\left[\left(y_{2}-y_{2}^{*}\right)-\frac{y_{2}}{y_{1}}\left(y_{1}-y_{1}^{*}\right)\right]\right. \\
&\left.-a_{1}\left(y_{1}-y_{1}^{*}\right)^{2}+\frac{\sigma_{1}^{2}}{2}\left(y_{1}-y_{1}^{*}\right)^{2}\right\} \\
&+ c_{3}\left\{\left(y_{2}-y_{2}^{*}\right) \frac{b}{y_{2}^{*}}\left[\left(y_{1}-y_{1}^{*}\right)-\frac{y_{1}}{y_{2}}\left(y_{2}-y_{2}^{*}\right)\right]\right. \\
&\left.-a_{2}\left(y_{2}-y_{2}^{*}\right)^{2}+\frac{\sigma_{2}^{2}}{2}\left(y_{2}-y_{2}^{*}\right)^{2}\right\} \\
&+\left(y_{2}-y_{2}^{*}\right) \frac{\left(1+n x^{*}\right)\left(x-x^{*}\right)-n x^{*}\left(y_{2}-y_{2}^{*}\right)}{\left(1+m x+n y_{2}\right)\left(1+m x^{*}+n y_{2}^{*}\right)} \\
&+ c_{1} q\left(x-x^{*}\right) \frac{m y_{2}^{*}\left(x-x^{*}\right)-\left(1+m x^{*}\right)\left(y_{2}-y_{2}^{*}\right)}{\left(1+m x+n y_{2}\right)\left(1+m x^{*}+n y_{2}^{*}\right)} \\
&+c_{1} \beta\left(x-x^{*}\right)^{2}+c_{1} \frac{\sigma^{2}}{2}\left(x-x^{*}\right)^{2} .
\end{aligned}
$$

Set $c_{2}=y_{1}^{*} / \alpha, c_{3}=y_{2}^{*} / b, c_{1}=c_{3} p\left(1+n x_{2}^{*}\right) / q\left(1+m y^{*}\right)=$ $\left(y_{2}^{*} / b\right)(p / q)\left(\left(1+m x^{*}\right) /\left(1+n y^{*}\right)\right)$. Then we have

$$
\begin{aligned}
L V= & \left\{-\frac{y_{2}}{y_{1}}\left(y_{1}-y_{1}^{*}\right)^{2}+2\left(y_{1}-y_{1}^{*}\right)\left(y_{2}-y_{2}^{*}\right)\right. \\
& \left.-\frac{y_{1}}{y_{2}}\left(y_{2}-y_{2}^{*}\right)^{2}\right\}-c_{2}\left(a_{1}-\frac{\sigma_{1}^{2}}{2}\right)\left(y_{1}-y_{1}^{*}\right)^{2} \\
& -c_{3}\left(a_{2}-\frac{\sigma_{2}^{2}}{2}\right)\left(y_{2}-y_{2}^{*}\right)^{2} \\
& -\frac{c_{3} p n x^{*}\left(y_{2}-y_{2}\right)^{2}}{\left(1+m x+n y_{2}\right)\left(1+m x^{*}+n y_{2}^{*}\right)} \\
& -c_{1}\left(\beta-\frac{\sigma^{2}}{2}\right)\left(x-x^{*}\right)^{2} \\
& +\frac{c_{1} q y_{2}^{*} m\left(x-x^{*}\right)^{2}}{\left(1+m x+n y_{2}\right)\left(1+m x^{*}+n y_{2}^{*}\right)}
\end{aligned}
$$




$$
\begin{aligned}
\leq & -\left[\sqrt{\frac{y_{2}}{y_{1}}}\left(y_{1}-y_{1}^{*}\right)-\sqrt{\frac{y_{1}}{y_{2}}}\left(y_{2}-y_{2}^{*}\right)\right]^{2} \\
& -\frac{y_{1}^{*}}{\alpha}\left(a_{1}-\frac{\sigma_{1}^{2}}{2}\right)\left(y_{1}-y_{1}^{*}\right)^{2} \\
& -\left(\frac{y_{2}^{*}}{b} a_{2}-\frac{y_{2}^{*}}{b} \frac{\sigma_{2}^{2}}{2}\right)\left(y_{2}-y_{2}^{*}\right)^{2}-\frac{y_{2}^{*}}{b} \frac{p}{q} \frac{1+n x^{*}}{1+m y^{*}} \\
& \times\left(\beta-\frac{\sigma^{2}}{2}-\frac{q m y_{2}^{*}}{1+m x^{*}+n y_{2}^{*}}\right)\left(x-x^{*}\right)^{2} \\
\leq & -\frac{y_{1}^{*}}{\alpha}\left(a_{1}-\frac{\sigma_{1}^{2}}{2}\right)\left(y_{1}-y_{1}^{*}\right)^{2}-\frac{y_{2}^{*}}{b}\left(a_{2}-\frac{\sigma_{2}^{2}}{2}\right) \\
& \times\left(y_{2}-y_{2}^{*}\right)^{2}-\frac{y_{2}^{*}}{b} \frac{p}{q} \frac{1+m x^{*}}{1+n y^{*}} \\
& \times\left(\beta-\frac{\sigma^{2}}{2}-\frac{q m y_{2}^{*}}{1+m x^{*}+n y_{2}^{*}}\right)\left(x-x^{*}\right)^{2} .
\end{aligned}
$$

The condition in Theorem 2 implies $L V \leq 0$, and the identity holds if and only if $\left(x, y_{1}, y_{2}\right)=\left(x^{*}, y_{1}^{*}, y_{2}^{*}\right)$. By Theorem 2.1 in [9] and the description of that theorem, we get the conclusion.

\section{Numerical Simulations}

In this section, we will use the Euler method and the Milstein method mentioned in [10] to substantiate the analytical findings. For system (4), consider the discretization equations

$$
\begin{aligned}
& x^{(k+1)}-x^{(k)}=x^{(k)}\left(\gamma-\frac{q y_{2}^{(k)}}{1+m x^{(k)}+n y_{2}^{(k)}}-\beta x^{(k)}\right) \\
& +\sigma x^{(k)}\left(x^{(k)}-x^{*}\right) \sqrt{\Delta t} \xi^{(k)} \\
& +\frac{\sigma^{2}}{2}\left(x^{(k)}-x^{*}\right)\left[\left(\xi^{(k)}\right)^{2}-1\right] \\
& y_{1}^{(k+1)}-y_{1}^{(k)}=\left[\alpha y_{2}^{(k)}-d_{1} y_{1}^{(k)}-a_{1}\left(y_{1}^{(k)}\right)^{2}-b y_{1}^{(k)}\right] \Delta t \\
& -\sigma_{1} y_{1}^{(k)}\left(y_{1}^{(k)}-y_{1}^{*}\right) \sqrt{\Delta t} \zeta^{(k)} \\
& +\frac{\sigma_{1}^{2}}{2}\left(y_{1}^{(k)}-y_{1}^{*}\right)\left[\left(\zeta^{(k)}\right)^{2}-1\right], \\
& y_{2}^{(k+1)}-y_{2}^{(k)}=\left[b y_{1}^{(k)}-d_{2} y_{2}^{(k)}-a_{2}\left(y_{2}^{(k)}\right)^{2}\right. \\
& \left.+\frac{p y_{2}^{(k)} x^{(k)}}{1+m x^{(k)}+n y_{2}^{(k)}}\right] \Delta t
\end{aligned}
$$

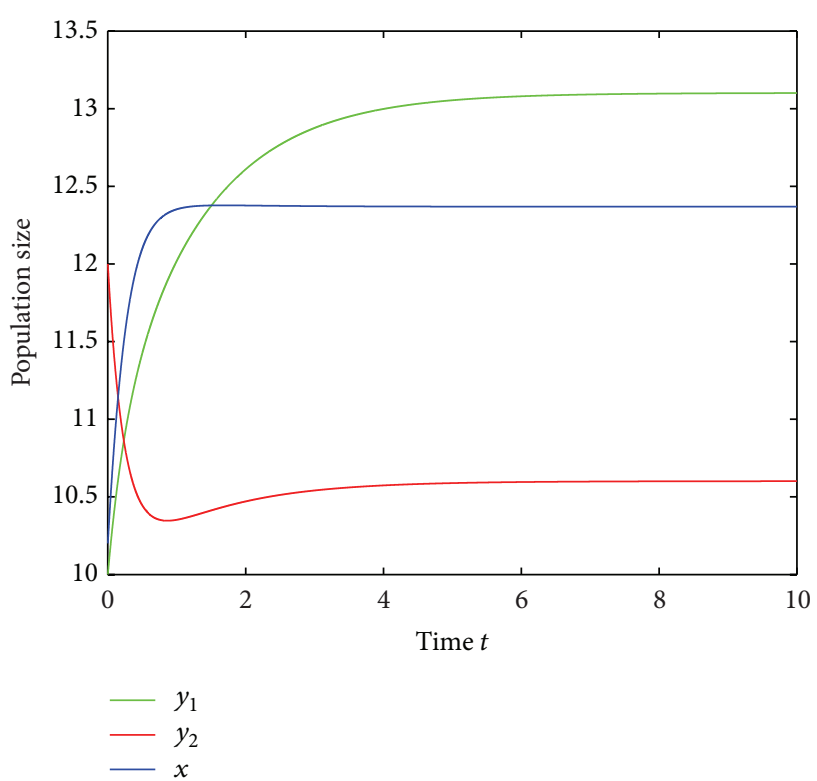

FIgURE 1: The solution of (2) with initial values $x(0)=10, y_{1}(0)=$ $10, y_{2}(0)=12$.

$$
\begin{aligned}
& -\sigma_{2} y_{2}^{(k)}\left(y_{2}^{(k)}-y_{2}^{*}\right) \sqrt{\Delta t} \eta^{(k)} \\
& +\frac{\sigma_{2}^{2}}{2}\left(y_{2}^{(k)}-y_{2}^{*}\right)\left[\left(\eta^{(k)}\right)^{2}-1\right],
\end{aligned}
$$

where $\xi^{(k)}, \zeta^{(k)}, \eta^{(k)}, k=1,2, \ldots, n$ are the Gaussian random variables which follow $N(0,1)$.

In Figure 1, we show the dynamics of the deterministic model with parameters $\alpha=1.2, d_{1}=0.26, b=0.58, a_{1}=$ $0.01, q=1.5, p=1, \beta=0.375, d_{2}=0.32, a_{2}=0.13, m=1$, $n=0.081, \gamma=5.9, \sigma=\sigma_{1}=\sigma_{2}=0$; then $x^{*}=12.37$, $y_{1}^{*}=13.1, y_{2}^{*}=10.6$.

In Figure 2, we choose the same parameter values as Figure 1 except that $\sigma=0.4, \sigma_{1}=0.45, \sigma_{2}=0.375$, which satisfy the condition in Theorem 2, so Figure 2 clearly supports the conclusion of Theorem 2 .

In Figure 3, we choose $\alpha=0.9, d_{1}=0.34, b=0.4, q=0.9$, $p=0.4, \beta=0.15, d_{2}=0.12, a_{1}=0.1, a_{2}=0.6, m=0.8, n=$ $0.5, \gamma=0.75, \sigma=\sigma_{1}=\sigma_{2}=0$; then $x^{*}=3.066, y_{1}=1.157$, $y_{2}=1.1$; in Figure 4, we choose the same parameter values as Figure 1 except that $\sigma_{1}=0.2 ; \sigma_{2}=0.42 ; \sigma_{3}=0.25$. So the conditions of our theoretical results hold. Obviously, the numerical simulations are indeed confirming our analytical results.

\section{Discussion}

In this paper, a stochastic predator-prey model with stage structure for the predator has been proposed and investigated. We discuss the biological significance of the model and establish sufficient conditions for global asymptotic stability of the model. These results are important because from the biological point of view, a global stable positive equilibrium 


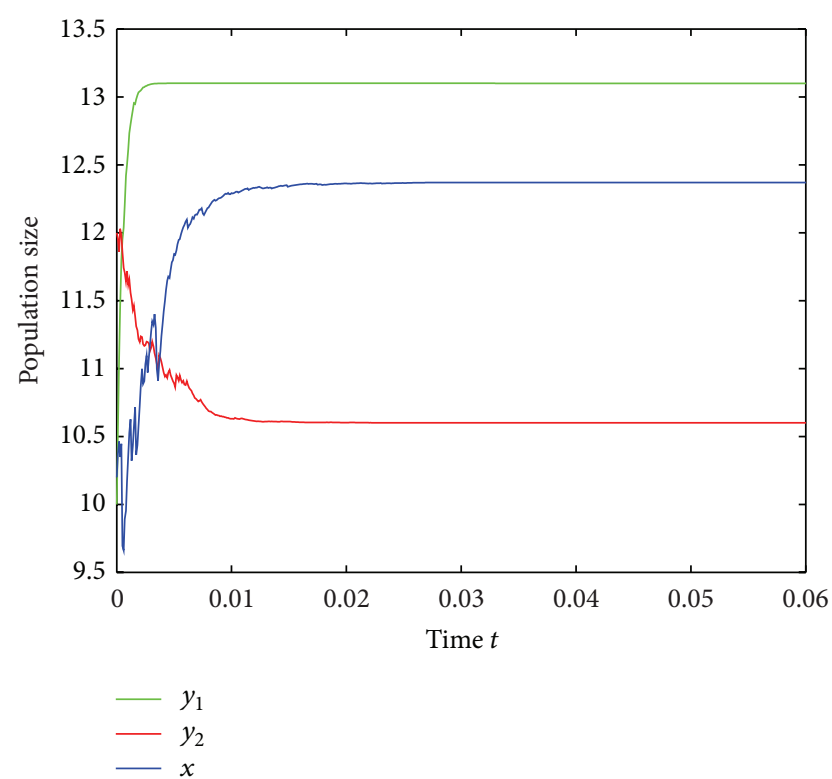

FIgURE 2: The solution of the stochastic model (4) with the same parameters as in Figure 1.

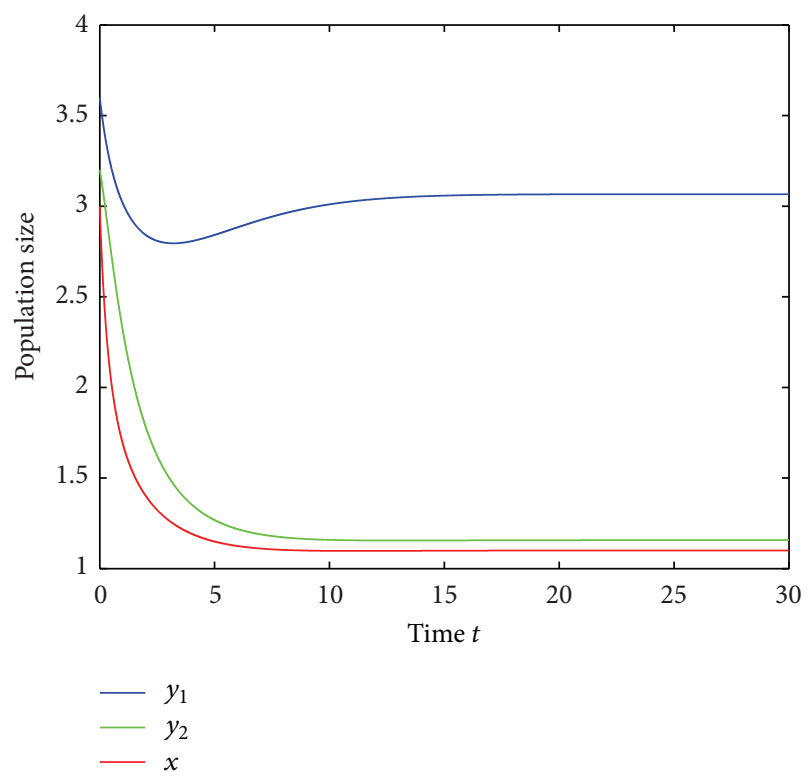

FIgURE 3: The solution of (2) with initial values $x(0)=3, y_{1}(0)=$ $3.6, y_{2}(0)=3.2$.

means that the community consisting of two species is a stable biotic community in which all species will coexist. To the best of our knowledge, the present paper is the first attempt to study system (4).

Although we only consider the global stability of the positive equilibrium, some interesting questions deserved investigation, like the stage structure effect on the long term behavior of the system. In fact, in (4) we have supposed that the predator is not only feeding on prey; we can also discuss the case in which the predator feeds on prey only. We want to

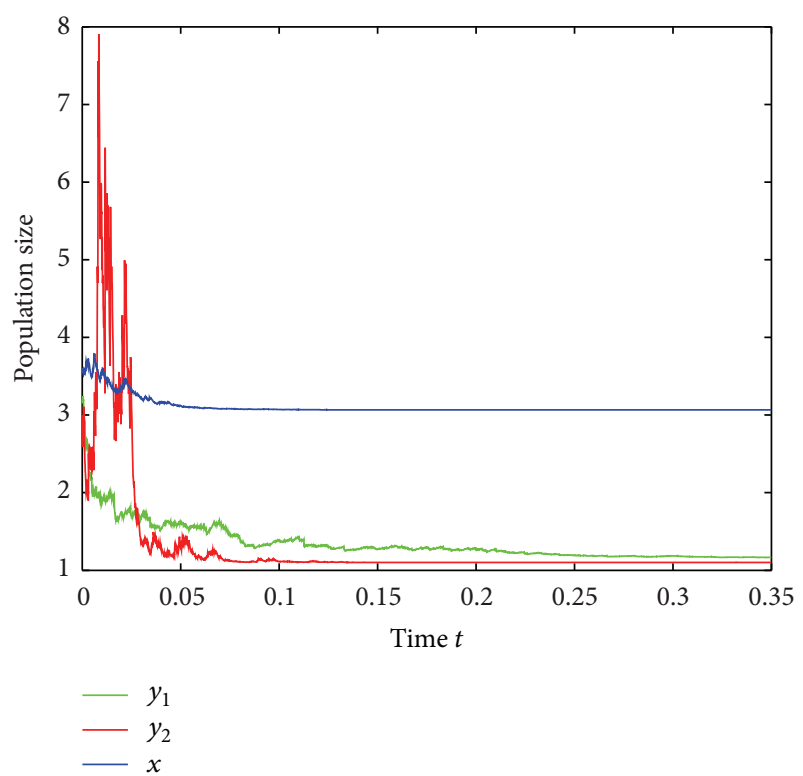

FIGURE 4: The solution of the stochastic model (4) with the same parameters as in Figure 3.

mention that we are unable to give the sufficient conditions under which system (4) or (2) has a positive equilibrium, for there are some technical obstacles that cannot be overcome at present stage. However, the values in Figure 1 show that the system (2) has the positive equilibrium position in some case, and we leave this for future work.

\section{Conflict of Interests}

The authors declare that there is no conflict of interests regarding the publication of this paper.

\section{References}

[1] J. R. Beddington, "Mutual interference between parasities and its effect on searching efficiency," Journal of Animal Ecology, vol. 44, pp. 331-341, 1975.

[2] D. L. DeAngelis, R. A. Goldsten, and R. Neil, "A model for trophic interaction," Ecology, vol. 56, pp. 88-92, 1975.

[3] P. Georgescu and Y.-H. Hsieh, "Global dynamics of a predatorprey model with stage structure for the predator," SIAM Journal on Applied Mathematics, vol. 67, no. 5, pp. 1379-1395, 2007.

[4] R. M. May, Stability and Complexity in Model Ecosystems, Princeton University Press, Princeton, NJ, USA, 2001.

[5] M. Liu and K. Wang, "Global stability of stage-structured predator-prey models with Beddington-DeAngelis functional response," Communications in Nonlinear Science and Numerical Simulation, vol. 16, no. 9, pp. 3792-3797, 2011.

[6] M. Liu and K. Wang, "Analysis of a stochastic autonomous mutualism model," Journal of Mathematical Analysis and Applications, vol. 402, pp. 392-403, 2013.

[7] M. Liu and K. Wang, "Stochastic Lotka-Volterra systems with Lévy noise," Journal of Mathematical Analysis and Applications, vol. 410, no. 2, pp. 750-763, 2014. 
[8] X. Mao, Stochastic Differential Equations and Their Applications, Horwood, Chichester, UK, 1997.

[9] X. Mao, "Stochastic versions of the LaSalle theorem," Journal of Differential Equations, vol. 153, no. 1, pp. 175-195, 1999.

[10] D. J. Higham, "An algorithmic introduction to numerical simulation of stochastic differential equations," SIAM Review, vol. 43 , no. 3, pp. 525-546, 2001. 


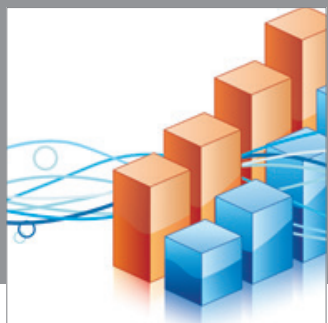

Advances in

Operations Research

mansans

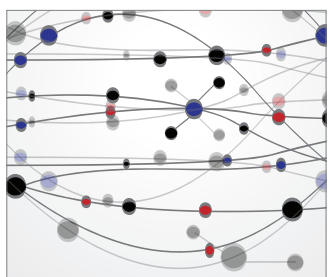

The Scientific World Journal
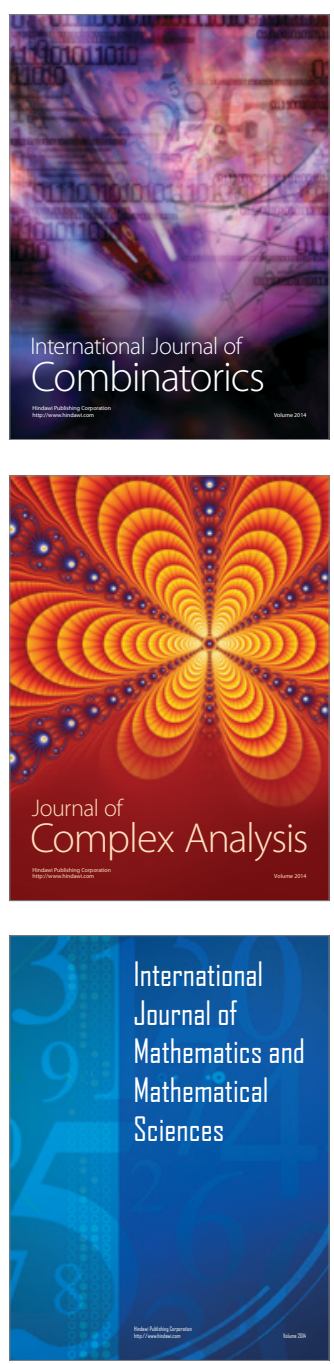
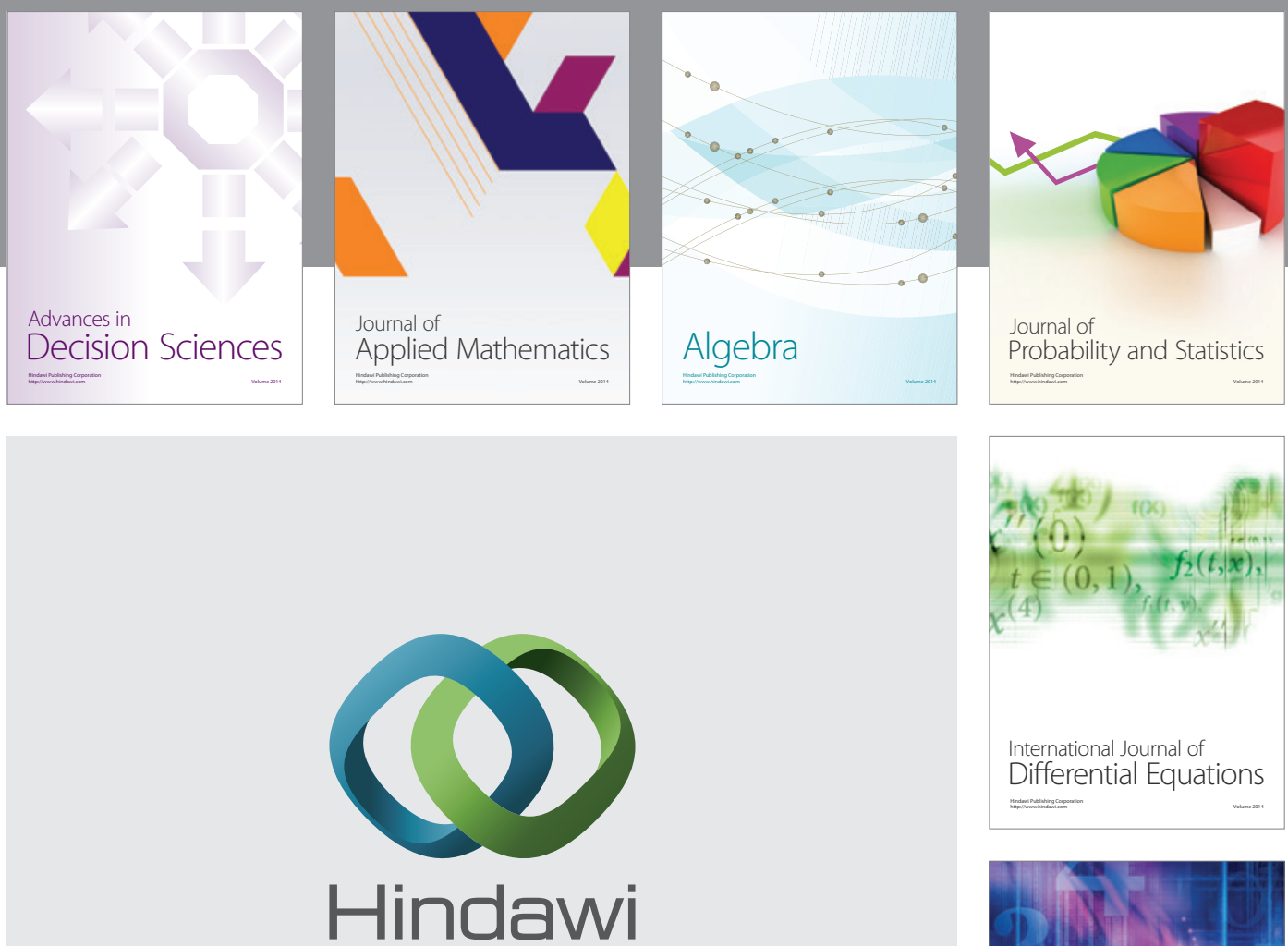

Submit your manuscripts at http://www.hindawi.com
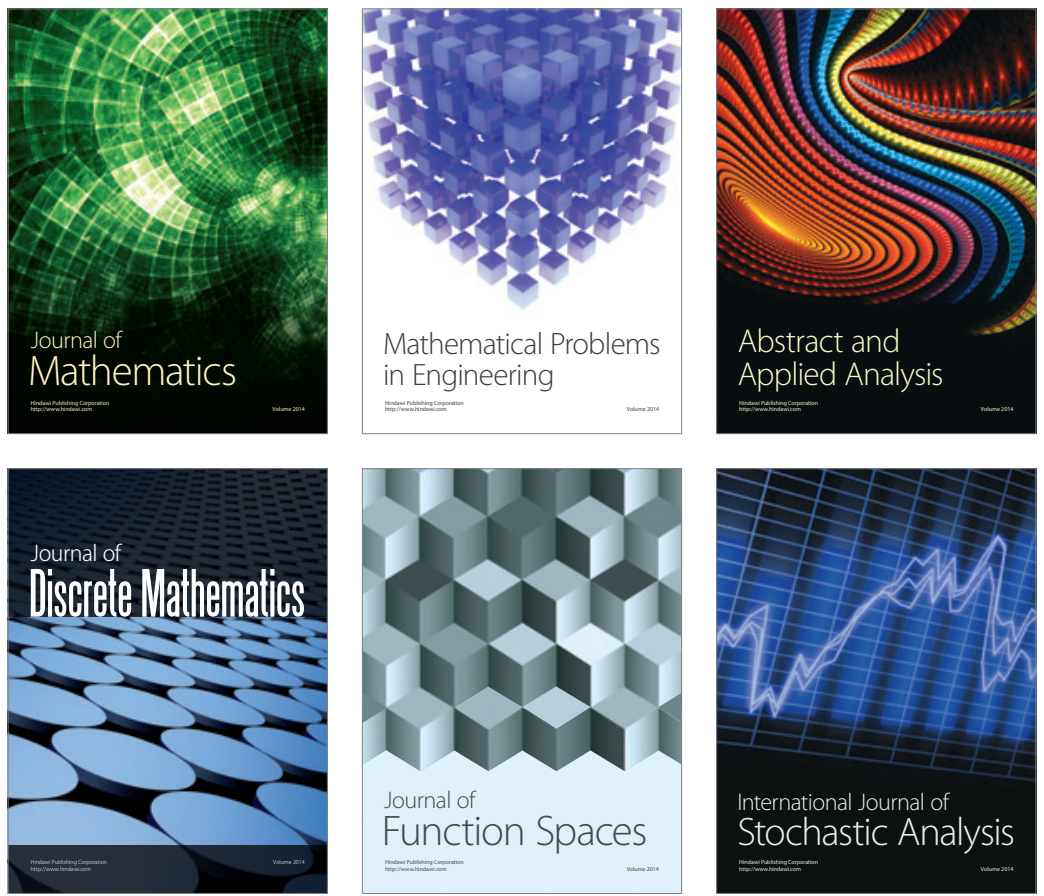

Journal of

Function Spaces

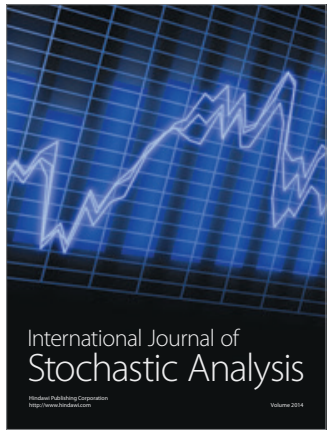

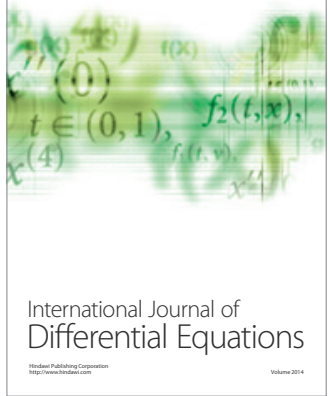
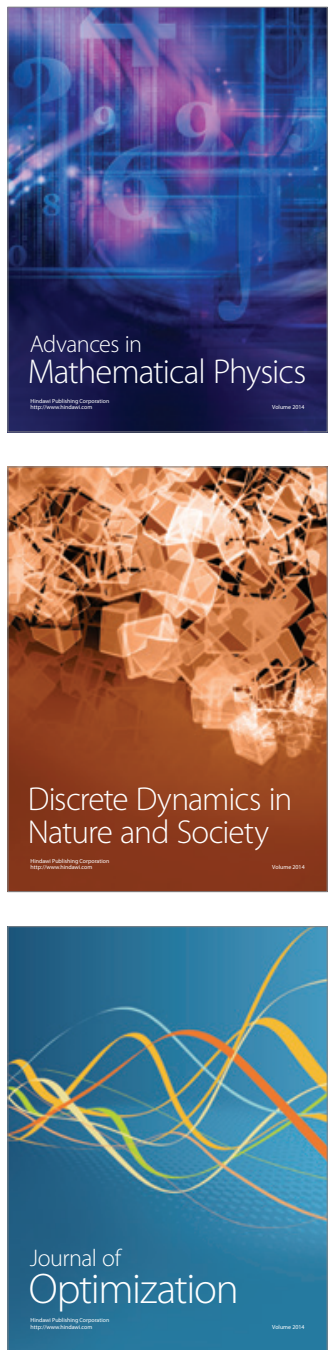